\title{
Programa de avaliação da Educação Básica do Espírito Santo: repercussões nas escolas e no Ensino de matemática
}

Rosiane Pereira Lima a Lúcio Souza Fassarella ${ }^{b}$

\section{Resumo}

Investigamos o Programa de Avaliação Diagnóstica da Aprendizagem (Paebes TRI) com o objetivo de identificar e discutir suas repercussões nas escolas e no processo de Ensino e de aprendizagem da matemática. Constitui pesquisa qualitativa do tipo descritiva e documental conduzida à luz da História Cultural, baseada na análise de leis, portarias e documentos da Secretaria da Educação do Espírito Santo (Sedu). A partir de dados e apontamentos fornecidos por textos acadêmicos pertinentes, incluindo dissertações, teses, livros e artigos, concluise que essa avaliação tem repercutido negativamente no ambiente escolar em três vertentes principais: (1) desvirtua o processo de avaliação dos alunos nas escolas, (2) estimula práticas precárias de Ensino e (3) reduz a autonomia dos professores na elaboração e execução dos planos de Ensino, criando a tendência para uma abordagem tradicional.

Palavras-chave: Políticas Públicas. Avaliação Externa. Educação Básica.

\section{Introdução}

A Educação no Brasil tem sido palco de expectativas e de conflitos diversos. Dependendo da perspectiva, ela tem sido vista como um meio para inserção social, formação pessoal e profissional, desenvolvimento do pensamento crítico ou reflexivo, entre outras possibilidades. Naturalmente, os governos têm a responsabilidade de propor e implementar políticas públicas que permitam que as escolas cumpram os objetivos que a sociedade consolidou democraticamente, tais

\footnotetext{
a Secretaria de Educação do Estado do Espírito Santo, São Mateus, ES, Brasil.

b Universidade Federal do Espírito Santo, Campus São Mateus, ES, Brasil. 
como aqueles definidos na Lei de Diretrizes e Bases da Educação Nacional: "A Educação abrange os processos formativos que se desenvolvem na vida familiar, na convivência humana, no trabalho, nas instituições de Ensino e pesquisa, nos movimentos sociais e organizações da sociedade civil e nas manifestações culturais" (BRASIL, 1996, p. 1).

Professores, gestores escolares e mesmo os cidadãos comuns têm a responsabilidade de analisar as ações governamentais na área da Educação buscando amparar, aperfeiçoar ou mudar as iniciativas na perspectiva de torná-las mais efetivas com o que a sociedade necessita. Em particular, é premente verificar os impactos das avaliações externas no Ensino na Educação Básica. Isto posto, as repercussões das avaliações externas têm sido tema de diversas pesquisas atuais e muitas delas mostram que as iniciativas governamentais não geram os efeitos práticos pretendidos. Como exemplo, citamos essa constatação acerca dos programas governamentais relacionados ao Programa de Avaliação de Aprendizado Escolar (Paae) desenvolvido pelo governo em Minas Gerais no período de 2003 a 1014:

Verificou-se que, no período entre 2003 e 2014, as políticas educacionais da rede estadual foram influenciadas pelo modelo de Gestão por Resultados. Destacam-se nesse contexto, as avaliações externas implementadas pelo Simave [Sistema Mineiro de Avaliação da Educação Pública].

Entretanto, os estudos sobre esses programas vêm demonstrando que, no âmbito das práticas, os objetivos e a intencionalidade não têm se efetivado do modo como são planejados. Além disso, os resultados fundamentados nos instrumentos de avaliação, que são priorizados no modelo de gestão assumida, demonstram os limites dessa política na superação dos problemas vividos no Ensino Médio. Apesar dessa assimetria entre o dito e o feito, e dos resultados insatisfatórios, percebem-se mudanças no cotidiano das escolas, impulsionadas pela valorização dos testes padronizados, cada vez mais presentes nas práticas avaliativas dos professores (FERNANDES; GOMES, 2020, p. 401).

Com objetivos semelhantes aos de Fernandes e Gomes (2020), analisamos o Programa de Avaliação da Educação Básica do Espírito Santo (Paebes), instituído pelo governo do estado do Espírito Santo como instrumento de avaliação da Educação Básica e recurso para o planejamento didático dos professores nas escolas. Especificamente, desenvolvemos uma pesquisa qualitativa do tipo descritiva e 
documental, que teve como objetivo responder à seguinte questão norteadora: Como o Paebes tem afetado o cotidiano das escolas estaduais do Espírito Santo, particularmente no Ensino e na aprendizagem da disciplina Matemática?

Além dessa introdução, o artigo está organizado em quatro seções. Na seção dois, Fundamentação Teórico-Metodológica, caracterizamos a metodologia de pesquisa, definimos nossos pressupostos teóricos e descrevemos os documentos e referências empregados. Descrevemos na seção três, Constituição e Objetivos do Paebes, a implementação e as alterações desse programa a partir de 2009, com foco no Programa de Avaliação Diagnóstica da Aprendizagem (Paebes TRI), iniciado em 2015. Na seção quatro, Repercussões do Paebes no Ensino da Matemática, discutimos os impactos do programa nas escolas estaduais, a partir de dados levantados por pesquisas acadêmicas envolvendo professores. Por fim, na seção Considerações Finais, sintetizamos nossas conclusões e apresentamos breves ponderações.

\section{Fundamentação teórico-metodológica}

Segundo Gil (2008, p. 28), as pesquisas descritivas “[...] têm como objetivo primordial a descrição das características de determinada população ou fenômeno ou o estabelecimento de relações entre variáveis". Essa pesquisa possui enquadramento descritivo, mas não exclui aspectos explicativos, pois "algumas pesquisas descritivas vão além da simples identificação da existência de relações entre variáveis, pretendendo determinar a natureza dessa relação. Neste caso temse uma pesquisa descritiva que se aproxima da explicativa" (GIL, 2008, p. 28).

Lüdke e André (2014) discorrem sobre a análise documental como método de coleta de dados, esclarecendo que essa metodologia de pesquisa "busca identificar informações factuais nos documentos a partir de questões ou hipóteses de interesse" (p. 38). Para essas autoras, "são considerados documentos [...] desde leis e regulamentos, normas, pareceres, cartas, memorando, diários pessoais, autobiografias, jornais, revistas, discursos, roteiros de programas de rádio e televisão até livros, estatísticas e arquivos escolares" (LÜDKE; ANDRÉ, 2014, p. 45).

Ainda conforme Lüdke e André (2014, p. 47-48), “[...] a escolha dos documentos não é aleatória. Há geralmente alguns propósitos ou hipóteses guiando a sua seleção". Em conformidade com essa concepção, selecionamos como fontes documentais para embasar nossa pesquisa, dispositivos legais e documentos auxiliares pertinentes: a Lei Estadual ${ }^{\circ} 10.631$ (ESPÍRITO SANTO, 2017a), a Portaria $\mathrm{n}^{\circ}$ 064-R (ESPÍRITO SANTO, 2017d), a Portaria ${ }^{\circ}$ 019-R (ESPÍRITO SANTO 2018a), o Manual de Gestão (das escolas estaduais do Espírito Santo) 
(ESPÍRITO SANTO, 2017b), o Pacto pela Aprendizagem do Espírito Santo Paes (ESPÍRITO SANTO, 2019), relatórios do Paebes TRI (ESPÍRITO SANTO, 2018b). Esses documentos revelam as finalidades estabelecidas pelo governo estadual para o Paebes e para o Paebes TRI em todas as esferas do sistema de Ensino, bem como os resultados que vêm sendo alcançados e as sugestões propostas para sua utilização.

A partir do conhecimento da legislação, levantamos conjecturas preliminares acerca dos impactos do Paebes TRI no processo de Ensino-aprendizagem, as quais buscamos verificar ou refutar considerando informações apresentadas em recentes pesquisas acadêmicas de campo. Dessa forma, nossas conclusões resultam do confronto da legislação com dados empíricos por meio de uma análise crítica que incluiu expectativas próprias.

Para definir os trabalhos acadêmicos abordando as repercussões das avaliações diagnósticas no cotidiano das escolas do estado do Espírito Santo, realizamos uma busca irrestrita no Banco de Teses e Dissertações da Capes, em dezembro de 2019. A busca com a palavra-chave "PAEBES" retornou 17 trabalhos. Uma análise do conteúdo desses trabalhos revelou que o Paebes, geralmente, ocorre de modo incidental, sem tratar da sua repercussão nas escolas ou qualquer relação com a Matemática - a maioria deles abordaram a alfabetização. Todavia, duas dissertações de mestrado trataram do programa numa perspectiva promissora para nossas considerações: Oliveira Júnior (2013) e Pieri (2015).

Também consideramos em nossa análise os dados e apontamentos apresentados nas dissertações de Martins (2018) e Oliveira (2019), que realizaram pesquisas junto a professores dos municípios de São Mateus e Jaguaré, ambos no Espírito Santo.

Para fundamentar nossa discussão, empregamos os conceitos de estratégia e tática, conforme definidos por Certeau (1998). Enquanto estratégia designa a ação de um sujeito detentor de poder (por exemplo, o governo do Estado do Espírito Santo), a tática é a correspondente reação de qualquer um que esteja submetido a esse poder (e.g., os professores da Rede Estadual de Educação).

Muitas práticas cotidianas (falar, ler, circular, fazer compras ou preparar as refeições etc.) são do tipo tática. E também, de modo mais geral, uma grande parte das "maneiras de fazer": vitórias do "fraco" sobre o mais "forte" (os poderosos, a doença, a violência das coisas ou de uma ordem etc.), pequenos sucessos, artes de dar golpes, astúcias de "caçadores", mobilidades da mão de obra, simulações polimorfas, 
achados que provocam euforia, tanto poéticos quanto bélicos. [...] Essas táticas manifestam igualmente a que pontos a inteligência é indissociável dos combates e dos prazeres cotidianos que articula, ao passo que as estratégias escondem sob cálculos objetivos a sua relação com o poder que os sustenta, guardado pelo lugar próprio ou pela instituição (CERTEAU, 1998, p. 47).

Deve estar claro que estratégia e tática não são necessariamente antagônicas. Entretanto, o "fraco" geralmente não possui condições para confrontar o que lhes é imposto, na medida em que ele "não dispõe de base onde capitalizar os seus proveitos, preparar suas expansões e assegurar uma independência em face das circunstâncias"; portanto, "o fraco deve tirar partido de forças que lhe são estranhas" (CERTEAU, 1998, p. 46-47).

Em nossa análise, as avaliações externas são compreendidas como estratégias governamentais sobre as instituições de Ensino, independentemente de quais sejam seus objetivos. Também consideramos como táticas as reações dos professores e dos gestores das escolas espírito-santenses frente às avaliações externas e correspondentes normatizações determinadas pelo governo estadual.

\section{Constituição e objetivos do Paebes TRI}

O Paebes foi instituído pelo governo do estado do Espírito Santo em 2009, por meio da Secretaria de Estado da Educação (Sedu) em parceria com o Centro de Políticas Públicas e Avaliação da Educação, da Universidade Federal de Juiz de Fora (CAEd/UFJF). Constitui um processo contínuo de avaliação e aperfeiçoamento da Educação Básica, cuja base está na aplicação de provas externas para os alunos de todas as escolas públicas estaduais e também àquelas escolas municipais ou particulares que aderirem. Por meio do programa se pretende

[...] observar o desempenho de estudantes por meio de testes padronizados, cujo objetivo é aferir o que eles sabem e são capazes de fazer, a partir da identificação do desenvolvimento de habilidades e competências consideradas essenciais para que consigam avançar no processo de escolarização. [...] Com ampla cobertura, percorrendo desde a alfabetização - Paebes Alfa - até os anos finais do Ensino Fundamental $-5^{\circ}$ e $9^{\circ}$ anos - e do Ensino Médio ( $3^{\mathrm{a}}$ série), o programa avalia várias disciplinas, com o intuito de medir com maior precisão a qualidade do Ensino ofertado. Com calendário fixo anual em língua portuguesa (leitura e escrita), produção de texto e matemática, e cronograma alternado em ciências da natureza 
(biologia, física e química) e ciências humanas (história e geografia) (ESPÍRITO SANTO, 2017b, p. 6-8).

A Sedu avançou sua estratégia de avaliação externa com a instituição em 2015 do Programa de Avaliação Diagnóstica da Aprendizagem (Paebes TRI), o qual prevê a aplicação de provas trimestrais para avaliação de todas as séries do Ensino Médio Regular ( $1^{\mathrm{a}}, 2^{\mathrm{a}}$ e $3^{\mathrm{a}}$ séries) e Integrado $\left(1^{\mathrm{a}}, 2^{\mathrm{a}}, 3^{\mathrm{a}}\right.$ e $4^{\mathrm{a}}$ séries $)$ da rede estadual ${ }^{1}$. O artigo $1^{\circ}$ da Portaria 064-R de 24/05/2017 define os objetivos do Paebes TRI:

I - Oferecer informações diagnósticas que viabilizem o planejamento pedagógico de acordo com o estágio de desenvolvimento dos alunos em cada trimestre letivo;

II - Oferecer subsídios sobre o desenvolvimento dos alunos para intervenções em tempo real, que promovam a melhoria da aprendizagem, da prática docente e do Ensino, durante o ano letivo (ESPÍRITO SANTO, 2017c, p. 19).

Em consonância com esses objetivos, o então secretário de Educação Haroldo Rocha resumiu a estratégia do programa ao Jornal Folha Vitória:

Os alunos fazem avaliações no primeiro, segundo e terceiro trimestres. É aplicada prova nos alunos. A correção é feita rapidamente para que professores saibam como estão os alunos. A partir dessa avaliação, os professores se programam para agir, melhorar a metodologia pedagógica. Todos os três eixos dizem respeito à melhoria estratégica da Educação (2015, p. 01).

Dando continuidade às iniciativas em prol da Educação, em 2017 foi instituído o Paes, pela Lei Estadual no 10.631 de 28/03/2017 (ESPÍRITO SANTO, 2017a). O Paes está estruturado em três eixos de ação, definidos no site oficial da Sedu como:

Apoio à gestão: compreende ações relacionadas ao desenvolvimento de habilidades voltadas ao fortalecimento da gestão em seus mais diversos níveis, ou seja, desde as secretarias municipais até a gestão do tempo e dos espaços pedagógicos em sala de aula. Abrange a construção, a compreensão, a disseminação e o monitoramento de indicadores e metas de qualidade da Educação;

O Ensino Médio Integrado se refere aos Cursos de Educação Profissional Técnica de Nível Médio oferecidos pela Secretaria de Estado da Educação nas escolas estaduais. 
Fortalecimento da Aprendizagem: trata-se de desenvolvimento de estratégias relacionadas diretamente ao fazer pedagógico nas unidades escolares. Define-se por estabelecer rotinas claras de formação, monitoramento, avaliação, além do apoio à disseminação de práticas pedagógicas exitosas;

Planejamento e Suporte: abrange ações relacionadas a estudos referentes à reorganização da oferta educacional nos municípios de maneira a garantir a otimização da alocação de recursos didáticos, humanos, financeiros e materiais. Compreende, ainda, análises referentes a demanda por vagas e necessidade de aparelhamento da rede de Educação Infantil, entre outros (ESPÍRITO SANTO, 2019, p. 1).

De acordo com a Lei no 10.631 (ESPÍRITO SANTO, 2017a), uma das ações do Paes é a produção de indicadores e metas de qualidade da Educação por meio de ações pedagógicas conjuntas, aproveitando a estrutura para fornecimento de material estruturado, formação continuada, currículo e avaliação. Com isso, passou a ser responsável pelo Paebes TRI.

Segundo a Sedu (ESPÍRITO SANTO, 2017b, p. 22), a avaliação externa "é um dos principais instrumentos para a elaboração de políticas públicas dos sistemas de Ensino e redirecionamento das metas das unidades escolares" e seu resultado é "uma medida de proficiência que possibilita aos gestores a implementação de políticas públicas, e às unidades escolares um diagnóstico de seu desempenho". A Sedu considera o Paebes TRI um projeto inovador, que propicia "formas de apoio do trabalho do professor no seu cotidiano com informações importantes para responder prontamente às necessidades e planejamento e ação no âmbito da sala de aula" (ESPÍRITO SANTO, 2017b, p. 26). Em conformidade com isso, os resultados são disponibilizados às escolas em um site de acompanhamento ${ }^{2} \mathrm{e}$ também em uma plataforma digital ${ }^{3}$, relacionando os descritores e as respostas de cada um dos alunos, considerando o percentual de acertos.

As funções do Paebes e do Paebes TRI sofreram importantes reformulações com a Portaria ${ }^{\circ}$ 064-R de 24/05/2017, que criou o Sistema Capixaba de Avaliação da Educação Básica (Sicaeb), composto por três pilares: o Paebes,

\footnotetext{
2 PROGRAMA DE VALIAÇÃO DA EDUCAÇÃO BÁSICA DO ESPIRÍTO SANTO - PAEBES. O Programa: matriz de referência. Dispontível em: http://www.paebes.caedufjf.net/. Acesso em: 7 ago. 2019.

3 ESPÍRITO SANTO. Secretaria de Estado da Educação. Foco Escola. Disponível em: http://www.educacaoemfoco. sedu.es.gov.br/login. Acesso em: 7 ago. 2019.
} 
o Paebes TRI e o Indicador de Desenvolvimento Escolar - IDE (ESPÍRITO SANTO, 2017c, p. 18). O aspecto prático mais importante da portaria está em determinar que o PAEBES TRI seja levado em conta na atribuição de nota aos alunos da rede estadual:

Art. $5^{\circ}$ Os resultados das avaliações do PAEBES TRI serão utilizados como parte da avaliação de cada trimestre letivo na rede estadual, nas séries/anos e disciplinas em que o exame for aplicado.

$\S 1^{\circ} \mathrm{A}$ avaliação de que trata o caput deste artigo deverá ser registrada como uma das avaliações do trimestre letivo da disciplina avaliada, além das três avaliações previstas no Regimento Comum das Escolas da Rede Estadual de Ensino (ESPÍRITO SANTO, 2017c, p. 18).

O caderno de questões do Paebes TRI é composto por 52 questões, sendo 26 de Língua Portuguesa e 26 de Matemática. Como a prova tem duração de 120 minutos, o tempo médio para a resolução de cada questão (incluindo o preenchimento do gabarito) é de cerca de 2 minutos e meio.

Com a Portaria $\mathrm{n}^{\circ}$ 064-R (ESPÍRITO SANTO, 2017c), 20\% da pontuação dos alunos passou a ser vinculada à avaliação externa, uma margem considerável que não pode ser desprezada - afinal, são as notas que determinam a aprovação ou reprovação dos estudantes. Especificamente, a pontuação máxima atribuída ao Paebes TRI seria de 6 pontos no $1^{\circ}$ e $2^{\circ}$ trimestres e 8 pontos no $3^{\circ}$ trimestre letivo, de acordo com o Quadro I.

Quadro 1 - Quantitativo de pontos a serem atribuídos em cada trimestre em relação ao percentual de acertos no Paebes TRI, de acordo com a Portaria $n^{\circ}$ 064-R

\begin{tabular}{|l|c|c|c|}
\hline \multirow{2}{*}{ Trimestre } & \multicolumn{3}{|c|}{ Parâmetros } \\
\cline { 2 - 4 } & Até $\mathbf{5 0 \%}$ de acertos & $\begin{array}{c}\text { Acima de } \mathbf{5 0 \%} \text { até } \mathbf{6 0 \%} \\
\text { de acertos }\end{array}$ & $\begin{array}{c}\text { Acima de } \mathbf{6 0} \% \\
\text { de acertos }\end{array}$ \\
\hline $1^{\circ}$ & 04 pontos & 05 pontos & 06 pontos \\
\hline $2^{\circ}$ & 04 pontos & 05 pontos & 06 pontos \\
\hline $3^{\circ}$ & 06 pontos & 07 pontos & 08 pontos \\
\hline
\end{tabular}

Fonte: Portaria ${ }^{\circ} 064-\mathrm{R}$ de 24/05/2017

As notas dos alunos eram atribuídas separadamente, de acordo com o número de acertos em cada disciplina. Sendo assim, como claramente exposto no Quadro 
I, um aluno que errasse todas as 26 questões de Matemática, obteria a mesma nota de um aluno que acertasse até $50 \%$ (13 questões); já a totalidade dos pontos poderia ser alcançada com apenas $60 \%$ de acertos - em torno de 16 questões.

A Portaria $n^{\circ}$ 019-R de 26/01/2018 (ESPÍTIRO SANTO, 2018a) modificou a atribuição das notas, conforme o Quadro 2.

Quadro 2 - Quantitativo de pontos a serem atribuídos em cada trimestre em relação ao percentual de acertos no Paebes TRI, de acordo com a Portaria n 019-R

\begin{tabular}{|l|c|c|c|c|}
\hline \multirow{2}{*}{ Faixas } & \multicolumn{2}{|c|}{$\mathbf{1}^{\mathbf{0}} \mathbf{\mathbf { 2 } ^ { \mathbf { 0 } } \text { trimestres }}$} & \multicolumn{2}{c|}{$\mathbf{3}^{\mathbf{0}}$ trimestre } \\
\cline { 2 - 5 } & \% Acertos & Pontuação & \% Acertos & Pontuação \\
\hline 01 & 0 & 0 & 0 & 0 \\
\hline 02 & 0 a 10 & 01 & 0 a 10 & 01 \\
\hline 03 & 11 a 20 & 02 & 11 a 20 & 02 \\
\hline 04 & 21 a 40 & 03 & 21 a 40 & 04 \\
\hline 05 & 41 a 60 & 04 & 41 a 60 & 06 \\
\hline 06 & 61 a 80 & 05 & 61 a 80 & 07 \\
\hline 07 & 81 a 100 & & 81 a 100 & 08 \\
\hline
\end{tabular}

Fonte: Portaria $\mathrm{n}^{\circ}$ 019-R de 26/01/2019

Como exposto no quadro acima, a Portaria ${ }^{\circ}$ 019-R tornou a atribuição de notas nas provas do Paebes TRI mais criteriosa. A partir dela, passou a ser necessário que os alunos tenham de $41 \%$ a $60 \%$ de acertos para obterem a pontuação média de pelo menos $81 \%$ de acertos para alcançar a nota máxima de cada trimestre.

A portarias $\mathrm{n}^{\circ}$ 064-R de 24/05/2017 (ESPÍRITO SANTO, 2017c) e ${ }^{\circ} 019-\mathrm{R}$ de 26/01/2018 (ESPÍTIRO SANTO, 2018a) fizeram com que o Paebes TRI deixasse de ser apenas um instrumento de avaliação diagnóstica (com base no desempenho dos estudantes) para se tornar fator constitutivo do processo de Ensino praticado nas escolas.

É importante salientar que o Paebes TRI possui uma Matriz de Referência composta por um conjunto de descritores que explicitam o conteúdo a ser avaliado em cada período de escolarização, bem como o nível de operação mental necessário para a realização de determinadas tarefas. Embora esteja baseada no Currículo Base da Rede Estadual, a Matriz de Referência difere dele, pois seus descritores são selecionados considerando aquilo que pode ser avaliado por meio de testes de múltipla escolha (ESPÍRITO SANTO, 2017b). Além disso, 
É importante compreender que as matrizes não abrangem todos os conhecimentos necessários para cada série, mas parte deles, representando um recorte das orientações curriculares da rede. Cada habilidade presente na matriz compreende determinado saber (fazer) e tem o propósito de identificar o desenvolvimento cognitivo mínimo esperado dos estudantes na etapa de escolaridade em questão (ESPÍRITO SANTO, 2018b, p. 13).

Conforme o calendário escolar, as provas do Paebes TRI são aplicadas cerca de três ou até quatro semanas antes do encerramento dos trimestres.

Diante disso, discutiremos a seguir, as repercussões do Paebes TRI no Ensino da Matemática, considerando textos acadêmicos pertinentes, incluindo dissertações, teses, livros e artigos.

\subsection{Repercussões do Paebes nas escolas e no Ensino de Matemática}

Primeiramente, é importante admitir que as avaliações externas podem ser empregadas como instrumentos de controle do governo sobre o trabalho dos professores:

A avaliação é uma estratégia estatal que aparece como parte da produção de ideias de um campo social. Esta produção inclui as relações de poder. [...] A avaliação forma parte da regulação, controle e governo do estado [...] cumpre fins de "polícia", tanto se a considerarmos como parte do nobre propósito e desejo dos que procuram melhorar a escola, como se cremos que forma parte do aspecto mais obscuro da regulação social (POPKEWITZ, 1992, p. 95-7, apud DIAS SOBRINHO, 2003, p. 93).

Cabe destacar que o controle indireto do Estado no trabalho dos professores pode se efetivar pela ação daqueles que são diretamente responsáveis pela sua supervisão:

Quanto aos resultados desta investigação, pode-se afirmar que as avaliações externas, incorporadas no setor educacional - sobretudo com as reformas educacionais a partir dos anos de 1990 - delineiam uma nova lógica no trabalho dos docentes, indicando um controle da direção/supervisão sobre a ação do professor, voltada quase que exclusivamente para resolver o problema do baixo desempenho dos alunos (VIEIRA; FERNANDES, 2011, p. 129). 
A primeira repercussão do Paebes TRI nas escolas está em dificultar a tarefa dos professores trabalharem em tempo hábil todos os tópicos previstos na Matriz de Referência, devido às provas serem aplicadas semanas antes do final dos trimestres (conforme visto no final da seção anterior). Tal dificuldade é agravada em função dos diferentes tempos de aprendizagem, as defasagens e as dificuldades cognitivas individuais dos alunos.

A divergência entre os programas de Ensino das escolas e os programas das avaliações externas devem levar os professores a adaptarem seu trabalho de modo a tentar resolver o conflito, levando em conta a limitação do tempo disponível para tanto. Isso foi verificado num estudo de caso sobre as repercussões do Paebes na prática docente, realizado em São Mateus-ES, por Pieri (2015, p. 67-8):

Ao investigar e analisar as práticas pedagógicas dos professores de Português e Matemática em função do Paebes, das turmas dos terceiros anos do Ensino Médio da Escola Estadual de Ensino Fundamental e Médio Santo Antônio de São Mateus-ES, é possível perceber que embora o programa orienta [SIC] o sistema de Ensino e estabelece [SIC] suas diretrizes de aplicação e execução de conteúdos, há uma brecha na comunicação entre todos os envolvidos no processo, pois a medida que [SIC] os professores relatam falta de tempo para trabalhar todo o conteúdo estipulado até o dia da prova.

Naturalmente, a limitação no tempo disponível para trabalhar os conteúdos induz os professores a desenvolverem práticas de Ensino tradicionais ${ }^{4}$, o que também foi verificado em relação ao Paebes por Pieri (2015, p. 68): "Analisando ainda as metodologias dos professores das disciplinas contempladas [Português e Matemática], não houve mudanças de métodos de Ensino, mas um ajuste e adaptações ao manejo dos conteúdos, devido à estrutura e critérios estabelecidos pelo programa".

É importante notar que os resultados do Paebes acabaram sendo opostos aos pretendidos, pois "os conteúdos são ministrados sem aprofundamentos, o que acarreta pouca atenção e comprometimento por parte dos alunos, deixando brechas no aprendizado" (PIERI, 2015, p. 69).

\footnotetext{
4 Para fixar as ideias, destacamos que no paradigma do exercício "[...] a aula de matemática é dividida em duas partes: primeiro, o professor apresenta algumas ideias e técnicas matemáticas e, depois, os alunos trabalham com exercícios selecionados. [...] existem variações nesse mesmo padrão: há desde o tipo de aula em que o professor ocupa a maior parte do tempo com exposição até aquela em que o aluno fica a maior parte do tempo envolvido com resolução de exercícios" (SKOVSMOSE, 2000, p. 67).
} 
Corroborando a tese de que o Paebes TRI deve apresentar problemas e resultados similares aos identificados por Pieri (2015) em relação ao Paebes. Apresentamos no Apêndice A, gráficos que sumariam os dados constantes nos relatórios do Paebes TRI referentes a 2018, ano em que uma média de $85 \%$ dos estudantes do Ensino Médio das escolas públicas estaduais realizou as provas nos três trimestres do ano letivo. A partir desses dados, verificamos que, apesar da inclusão dos resultados no Paebes TRI no cálculo das notas trimestrais ter levado a uma melhora no desempenho dos alunos na avaliação, a média geral de acertos em Matemática nas escolas da rede estadual tem oscilado entre $25 \%$ e $40 \%$, mesmo nas questões consideradas fáceis. Ou seja, os resultados do Paebes TRI 2018 mostram claramente que o desempenho dos estudantes ainda é insatisfatório, pelo que podemos concluir que essa avaliação em sua configuração atual não tem contribuído para a consecução dos seus propósitos motivadores.

Encontramos mais informações sobre as repercussões do Paebes TRI nas dissertações de Martins (2018) e Oliveira (2019), as quais relatam pesquisas realizadas com professores da Educação Básica.

Martins (2018) realizou uma pesquisa qualitativa do tipo exploratório-descritiva sobre o Ensino de Combinatória junto a professores do município de São Mateus - ES, buscando responder à pergunta: Quais são as representações do professor de Matemática sobre Combinatória e como elas repercutem na sua prática pedagógica? Entre as questões abordadas no estudo, figuraram as repercussões dos documentos oficiais e das avaliações externas. Segundo suas análises, "Os professores apontam a Matriz de Referência de Matemática como documento norteador da escolha e organização dos conteúdos a serem trabalhados em suas aulas, sentindo-se pressionados a ensinar o que pede o documento, para que os alunos estejam preparados, periodicamente, para o Paebes" (MARTINS, 2018, p. 92-3).

Cabe reproduzir aqui as falas de dois professores diretamente relacionadas aos documentos oficiais e Paebes, obtidas por meio de uma entrevista semiestruturada:

Os documentos influenciam sim, hoje mais do que antes, porque nós temos o Paebes que ranqueia as escolas e as turmas. Essa prova é estabelecida a cada trimestre e precisamos ensinar determinados conteúdos em um espaço de tempo (que muitas vezes não dá tempo) para que eles façam bem as provas (MARTINS, 2018, p. 93). 
[...] como esse assunto [Combinatória] é do Ensino Médio, eu busco muito trabalhar questões que já caíram no Paebes, que é a maior preocupação deles [os alunos] (MARTINS, 2018, p. 93).

Considerando a perspectiva teórica dada por Certeau (1994), Martins (2018) compreende (conforme exposto anteriormente) que as provas do Paebes constituem uma estratégia governamental para forçar os professores a trabalharem os conteúdos da Matriz de Referência, bem como são referidas taticamente pelos professores para justificar o modo como ensinam:

[...] podemos então conjecturar, a partir de Certeau (1994), que a prova é uma estratégia do governo para tentar forçar os professores a trabalharem os conteúdos como pedem na Matriz, ao mesmo tempo que é uma tática da professora afirmar que precisa trabalhar rapidamente os conteúdos, naquela ordem, justificando sua maneira de ensinar pelo fato de que precisa atender às expectativas desse órgão (MARTINS, 2018, p. 92-93).

Oliveira (2019) desenvolveu um estudo de caso etnográfico de natureza qualitativa, que teve como objetivo geral descrever e analisar as representações que emergiram de professores do $4^{\circ}$ e do $5^{\circ}$ anos, atuantes no município de Jaguaré-ES, imersos num processo de formação continuada em Matemática, tendo empregado como instrumentos para coleta de dados a entrevista e a observação participante. Essa pesquisa nos fornece várias informações acerca dos impactos das avaliações externas no cotidiano escolar, particularmente o Paebes. De modo geral,

[...] percebemos que os agentes externos ao trabalho docente, como currículo, RCNEI [Referencial Curricular Nacional para a Educação Infantil], PCN [Parâmetros Curriculares Nacionais] e as avaliações externas, podem interferir no desenvolvimento das práticas pedagógicas e na atuação do professor ao ensinar Matemática. A esse respeito, os professores expressaram que julgam necessária essa interferência, devido ao fato de nortear os trabalhos docentes, mas, frequentemente, questionam a necessidade da listagem extensa de conteúdos (OLIVEIRA, 2019, p. 121).

A pesquisa de Oliveira (2019, p. 78) aponta que os professores "demonstram a necessidade de prepará-los [os alunos] para futuras avaliações externas", bem como eles as utilizam como fontes de problemas para as aulas: 
Com as respostas coletadas, tomamos conhecimento de que, entre as fontes empregadas para a elaboração do planejamento das aulas, os docentes utilizavam, principalmente, o livro didático, mas não apenas ele. Afirmaram variar as fontes e, com frequência, fazer uso de provas externas encontradas em programas na Internet, como o Programa de Avaliação da Educação Básica do Espírito Santo (Paebes), pesquisas em sites educativos, questões trabalhadas em anos anteriores reformuladas, produções coletivas de problemas junto com a turma, criações do próprio professor e questões adaptadas da Internet para a realidade dos estudantes (OLIVEIRA, 2019, p. 40).

Analisando as representações dos professores acerca da avaliação do aluno, Oliveira (2019, p.125) observa que: "a representação da avaliação como instrumento de aprendizado, em que a produção do aluno deve ser valorizada e o erro considerado como parte importante do processo, foi confrontada, em diversos momentos, devido à necessidade de preparar o estudante para avaliações externas".

Nesse contexto, cabe reproduzir a fala de um professor que participou do curso de formação, que evidencia a influência das avaliações externas no processo de avaliação dos alunos realizado dentro das salas de aula: "Eu estabeleço critérios: um acerto para o desenvolvimento e um acerto para o resultado. Fica mais didático para explicar para a família e para o próprio aluno. Mas minha preocupação é que, no vestibular, isso não funciona assim. É muito contraditório" (OLIVEIRA, 2019, p. 125)!

Sobre essa questão, Oliveira $(2019$, p. 126) conclui que:

[...] essa visão que objetiva treinar os estudantes para avaliações externas, ao repudiar o erro não o considera como constituinte na construção do conhecimento matemático. Entretanto, ao pensarmos o processo como a Matemática se desenvolve ao longo do tempo, observamos que muitos trabalhos dos matemáticos consistem em investigações, que não são traçadas apenas pelos acertos.

Assim, percebemos como programas governamentais, como o Paebes e com o Paebes TRI, que visam melhorar a qualidade da Educação, podem provocar uma precarização do próprio processo de Ensino - na medida em que leva ao desvirtuamento desse processo, dificultando (ou até impedindo) que os professores possam empregar diferentes práticas educativas. 
O Paebes e o Paebes TRI também prejudicam o processo de avaliação do aprendizado nas escolas na medida em que suas provas possuem a configuração de uma avaliação tradicional, ou seja, está associada a uma hierarquia de excelência, que engloba as provas e os trabalhos comumente desenvolvidos durante o ano letivo, tendo o propósito de "medir" a aprendizagem por meio de notas e determinar o sucesso ou o fracasso escolar do estudante (PERRENOUD, 1999). Essas provas não incorporam e nem proporcionam estímulo para os professores implementarem um processo avaliativo que equilibre três funções essenciais, definidas por Haydt (2004): diagnosticar, controlar e classificar.

Essas concepções são corroboradas pelas constatações que Vieira e Fernandes (2011) obtiveram numa pesquisa com professores da cidade de Viçosa-MG: "Percebe-se que os testes em larga escala são modalidades de avaliação [externa] que estão presentes nas políticas educacionais como forma de gerar indicadores para a melhoria da Educação brasileira, mas que, na verdade, esses testes não promovem o desenvolvimento processual e integral do aluno" (p. 129-130).

Em consonância com Buriasco e Soares (2012, p.107), acreditamos que a preocupação dos professores com ensinar os alunos a responder questões de provas externas reduz o Ensino a um treinamento e não "[...] fornece [quanto aos alunos] informações sobre o seu processo de aprendizagem, nem indica os limites da interpretação do professor" - o que podemos entender como deturpação do trabalho docente.

No caso do Paebes TRI, algumas das inadequações gerais das avaliações externas se tornaram mais significativas a partir do momento em que seus resultados passaram a integrar as notas escolares dos alunos, posto que, com isso, a avaliação consolidou-se como mecanismo de influência e de controle das práticas didáticas desenvolvidas nas escolas, repercutindo indiretamente no currículo praticado.

Essa questão foi analisada numa pesquisa realizada na cidade de Moniz Freire - ES por Frinhani (2013), na qual se verificou que

Para $80 \%$ dos pedagogos seus objetivos educacionais estão voltados ao Programa Próprio de Avaliação do município [de Moniz Freire], distribuído entre melhorar os índices educacionais da escola, traçar metas de qualidade para as turmas e melhorar a qualidade das avaliações. E, apenas $20 \%$ indicou como objetivo a preocupação em proporcionar a aprendizagem dos alunos (p. 82). 
Coerente com a própria compreensão dos objetivos educacionais, os professores estudados por Frinhani (2013) focaram seu trabalho na melhoria dos índices de avaliação (em vez da aprendizagem dos alunos):

Para os pedagogos, $40 \%$ citaram como principal foco de seu trabalho melhorar os índices educacionais de suas escolas; $20 \%$ traçar metas de qualidade para as turmas e outros $20 \%$ melhorar a qualidade da avaliação. Com base nesses resultados observou-se novamente que $80 \%$ dos pedagogos entrevistados tem seu foco de trabalho apenas nas avaliações somativas e classificatórias, consequentemente, no aumento dos índices educacionais conforme relataram nas entrevistas (p. 83).

O resultado final dos problemas e distorções do processo de Ensino e aprendizagem verificados no Paebes por Pieri (2015) e no Programa Próprio de Avaliação do Município de Moniz Freire, por Frinhani (2013), levou a uma aprendizagem insatisfatória.

\section{Considerações finais}

O Paebes e o Paebes TRI são instrumentos criados pelo governo do Espírito Santo para melhorar a qualidade do Ensino realizado nas escolas públicas estaduais. O Paebes TRI consiste em uma avaliação da aprendizagem por meio de provas aplicadas trimestralmente, cujos resultados entram na composição das notas escolares dos alunos e devem ser utilizados pelos professores para identificar problemas no Ensino e desenvolver ações para superá-los. Amparados por algumas pesquisas de campo pertinentes e algumas referências da literatura da área, concluímos que essa estratégia governamental tem produzido, nos professores, táticas cujos efeitos vão de encontro aos objetivos declarados do programa, especialmente no que tange ao Ensino de Matemática: adoção de uma forma de Ensino minimalista e enfoque na avaliação externa em detrimento da avaliação formativa.

Especificamente, identificamos as seguintes repercussões do Paebes TRI no cotidiano das escolas públicas estaduais:

a) desvirtuamento do processo de avaliação dos alunos, na medida em que influencia no modo como os professores avaliam os erros nas provas escolares e compete com uma avaliação pessoal, contínua e integrada ao processo de aprendizagem; 
b) precarização das práticas de Ensino, por estimular nos professores a tendência pela abordagem tradicional em detrimento de metodologias alternativas, bem como por corroborar a ideia de que a Educação Básica se reduz à preparação para processos seletivos futuros (e.g., vestibular);

c) redução da autonomia dos professores na elaboração e execução dos planos de Ensino, particularmente por lhes induzir abordar os tópicos da Matriz de Referência num prazo compatível com o calendário das provas externas em detrimento das idiossincrasias da própria escola.

Naturalmente, as avaliações externas podem contribuir para melhorar a eficiência do Ensino realizado nas escolas, na medida em que fornecem aos professores dados que podem servir para desenvolver ações didáticas mais eficientes. Entretanto, pensando em termos de políticas públicas, as estratégias governamentais para o Ensino devem ser avaliadas quanto a todos os seus possíveis efeitos nos professores e nos alunos, posto que estes podem reativamente, adotar táticas contraproducentes. Em particular, é necessário que sejam integradas ao cotidiano escolar de modo que possam promover, em vez de desestimular, a autonomia dos professores no processo de Ensino e a consciência dos alunos sobre a importância do conhecimento que é ensinado.

Finalmente, professores e gestores da Educação precisam considerar que uma sala de aula reúne pessoas com diferentes temperamentos e inclinações; por isso, é necessário buscar e implementar modelos para o Ensino e para a avaliação que permitam identificar e abordar adequadamente dificuldades e potencialidades individuais, incluindo alunos e professores. As avaliações externas podem ser componentes importantes desses modelos, mas não podem figurar como elemento determinante de todo processo de Ensino e de aprendizagem.

Aqui percebemos a importância de o trabalho docente ser realizado em condições satisfatórias (para não dizer ótimas), pois: de que adianta identificar deficiências na aprendizagem se os professores estiverem sobrecarregados, sem tempo, sem recursos ou sem conhecimento didático para poder superá-las? 


\title{
Evaluation Program of Basic Education in Espírito Santo: repercussions in schools and mathematics Teaching
}

\begin{abstract}
This article investigates the Diagnostic Learning Assessment Program (Programa de Avaliação Diagnóstica da Aprendizagem - Paebes TRI) with the objective of identifying and discussing its repercussions in schools and in the mathematics teaching process. It constitutes qualitative research of the descriptive and documentary type conducted in the light of Cultural History, based on the analysis of laws, ordinances and documents of the State Secretariat of Education of Espírito Santo (Secretaria de Estado da Educação - Sedu). Based on data and notes provided by relevant academic texts, including dissertations, theses, books and articles, concludes that this evaluation has had a negative impact on the school environment in these three main ways: (1) it distorts the process of evaluating students in schools, (2) it encourages poor Teaching practices and (3) it reduces the autonomy of teachers in the elaboration and execution of Teaching plans, creating the tendency towards a traditional approach.
\end{abstract}

Keywords: Public Policies. External Evaluation. Basic education.

\section{Programa de evaluación de Educación Básica de Espírito Santo: repercusiones en las escuelas y la Enseñanza de las matemáticas}

\section{Resumen}

El artículo investiga el Programa de Evaluación de Educación Básica de Espírito Santo Programa de evaluación diagnóstica del aprendizaje (Programa de Avaliação Diagnóstica da Aprendizagem - Paebes TRI) con el objetivo de identificar y discutir sus repercusiones en las escuelas y en el proceso de enseñanza de las matemáticas. Constituye una investigación cualitativa de tipo descriptiva y documental realizada a la luz de la Historia Cultural, basada en el análisis de leyes, ordenanzas y documentos de la Secretaría de Estado de Educación de Espírito Santo (Secretaria de Estado da Educação-Sedu). Basado en datos y notas provistas por textos académicos relevantes, incluyendo disertaciones, tesis, libros y artículos, concluye que esta evaluación ha tenido un impacto negativo en el ambiente escolar en estas tres formas principales: (1) distorsiona el proceso de evaluación de los estudiantes en las escuelas, (2) fomenta las malas prácticas de Enseñanza y (3) reduce la autonomía de los docentes en la elaboración y ejecución de planes de Enseñanza, creando la tendencia hacia un enfoque tradicional.

Palabras clave: Politicas Públicas. Evaluación Externa. Educación Básica. 


\section{Referências}

BRASIL. Lei $\mathrm{n}^{\circ}$ 9.394, de 20 de dezembro de 1996. Estabelece as diretrizes e bases da educação nacional. Diário Oficial da União, Brasília, DF, 23 dez. 1996.

BURIASCO, R. L. C.; SOARES, M. T. C. Avaliação de Sistemas Escolares: da classificação dos alunos à perspectiva de análise de sua produção matemática. In: VALENTE, W. (org.). Avaliação em Matemática: história e perspectivas atuais. 2. ed. Campinas: Papirus, 2012. p. 101-142. (Coleção Magistério: Formação e Trabalho Pedagógico).

CERTEAU, M. A invenção do cotidiano: artes de fazer. 3. ed. Petrópolis: Vozes, 1998.

DIAS SOBRINHO, J. Avaliação: políticas educacionais e reformas da educação superior. São Paulo: Cortez, 2003.

ESPÍRITO SANTO. Lei Estadual n ${ }^{\circ} 10.631$, de 28 de março de 2017. Institui o Pacto pela Aprendizagem no Espírito Santo e dá outras providências. Diário Oficial do Estado, Vitória, 29 mar. 2017a. Disponível em: http://www3.al.es. gov.br/Arquivo/Documents/legislacao/html/LEI106312017.html. Acesso em: 18 ago. 2019.

ESPÍRITO SANTO. Secretaria de Estado da Educação. Manual de gestão: informações ao gestor escolar da rede estadual do Espírito Santo. Vitória, 2017b. Disponível em: https://sedu.es.gov.br/Media/sedu/pdf\%20e\%20 Arquivos/manuais/Manual\%20da\%20Gestão\%20completo.pdf. Acesso em: 12 ago. 2019.

ESPÍRITO SANTO. Secretaria de Estado da Educação. Pacto pela Aprendizagem no Espirito Santo - Paes. Vitória, 2019. Disponível em:. https:// sedu.es.gov.br/paes. Acesso em: 18 ago. 2019.

ESPÍRITO SANTO. Secretaria de Estado da Educação. PAEBES TRI Relatórios. Coleção 2018. Vitória, 2018b. Disponível em: http://www.paebes. caedufjf.net/colecoes/2018-2/. Acesso em: 24 ago. 2019.

ESPÍRITO SANTO. Secretaria de Estado da Educação. Portaria $N^{\circ} 019-R$, de 26 de janeiro de 2018. Diário Oficial do Estado, Vitória, 29 jan. 2018a. p. 13. Disponível em: https://sedu.es.gov.br/Media/sedu/pdf\%20e\%20Arquivos/ Portaria\%20020-R\%202018\%20-\%20Aulas\%20Dadas.pdf. Acesso em: 21 ago. 2019. 
ESPÍRITO SANTO. Secretaria de Estado da Educação. Portaria $n^{\circ} 064-R$, de 24 de maio de 2017. Institui o Sistema Capixaba de Avaliação da Educação Básica no âmbito do Sistema de Ensino do Espírito Santo - SICAEB. Diário Oficial do Estado, Vitória, 25 maio 2017c. p. 18-19. Disponível em: https://avaliacaoeducacional.files.wordpress.com/2017/08/portaria-n-064-rdio-25-05-2017.pdf. Acesso em: 14 ago. 2019.

FERNANDES, A. O.; GOMES, S. S. Entre o discurso e a prática docente: interfaces do Programa de Avaliação da Aprendizagem Escolar (Paae). Ensaio: Avaliação e Políticas Públicas em Educação, Rio de Janeiro, 2020, v. 28, n.107, p. 386-406, abr.-jun. 2020. https://doi.org/10.1590/s0104-40362020002801613

FRINHANI, P. E. Avaliação da Matemática Escolar em larga escala: reflexos na rede municipal de Munis Freire - ES. Dissertação (Mestrado - Educação em Ciências e Matemática) - Instituto federal do Espírito Santo, Vitória, ES, 2013.

GIL, A. C. Métodos e técnicas de pesquisa social. 6. Ed. São Paulo: Atlas, 2008.

HAYDT, R. C. C. Avaliação do processo ensino-aprendizagem. 6. ed. São Paulo: Ática, 2004. (Série Educação).

LÜDKE, M.; ANDRÉ, M. E. D. A. Pesquisa em Educação: abordagens qualitativas. 2. ed. São Paulo: EPU, 2014.

MARTINS, G. G. Ensino de análise combinatória: um estudo das representações de professores de matemática do Ensino Médio público de São Mateus. Dissertação (Mestrado em Ensino na Educação Básica) Universidade Federal do Espírito Santo, São Mateus, ES, 2018.

OLIVEIRA, A. V. Café com Matemática: representações de professores do $4^{\circ}$ e $5^{\circ}$ anos do Ensino Fundamental num processo de formação continuada sobre conteúdos e metodologias. Dissertação (Mestrado em Ensino na Educação Básica) - Universidade Federal do Espírito Santo, São Mateus, ES, 2019.

OLIVEIRA JUNIOR, R. B. As politicas educacionais do segundo mandato do Governo Paulo Hartung e seus impactos no trabalho docente. Dissertação (Mestrado em Educação) - Programa de Pós-graduação em Educação, Universidade Federal do Espírito Santo, Vitória, ES, 2013.

PERRENOUD, P. Avaliação: da excelência à regulação das aprendizagens: entre duas lógicas. Porto Alegre: Artes Médicas Sul, 1999. 
PIERI, L. A. R. Avaliação do PAEBES: a influência do Programa nas Práticas Pedagógicas: um estudo de caso. Dissertação (Mestrado Profissional em Gestão Social, Educação e Desenvolvimento Regional) - Faculdade Vale do Cricaré, São Mateus, ES, 2015.

ROCHA, H. "QUEM é contra, simplesmente por ser contra, não é aliado", diz secretário sobre Escola Viva. Folha Vitória, 10 de agosto ago. 2015. Disponível em: https://www.folhavitoria.com.br/geral/noticia/08/2015/queme-contra-simplesmente-por-ser-contra-nao-e-aliado-diz-secretario-sobreescola-viva. Acesso em: 14 fev. 2020.

SKOVSMOSE, O. Cenários para investigação. Bolema, Rio Claro, v. 13, n. 14, p. 66-91, 2000. Disponível em: http://www.periodicos.rc.biblioteca. unesp.br/index.php/bolema/article/view/1063. Acesso em: 7 ago. 2019.

VIEIRA, R. A.; FERNANDES, C. P. Avaliações externas em foco: percepções e efeitos para o trabalho docente. Educação em Perspectiva, Viçosa, v. 2, n. 1, p. 119-132, jan./jun. 2011. Disponível em: https://periodicos.ufv.br/ojs/ educacaoemperspectiva/ article/view/6496. Acesso em: 28 ago. 2019.

\section{Informações sobre os autores}

Rosiane Pereira Lima: Mestre em Ensino na Educação Básica pela Universidade Federal do Espírito Santo, professora do Ensino Médio na rede estadual da Secretaria de Educação do Estado do Espírito Santo. Contato: rosimat2014@gmail.com (iD) https://orcid.org/0000-0002-3026-909X

Lúcio Souza Fassarella: Doutor em Ciências Físicas pelo Centro Brasileiro de Pesquisas Físicas, professor do Programa de Pós-Graduação em Ensino na Educação Básica da Universidade Federal do Espírito Santo. Contato: lucio. fassarella@ufes.br"lucio.fassarella@ufes.br

(iD) http://orcid.org/0000-0001-6339-8958 


\section{APÊNDICE A - Resultados do Paebes TRI 2018}

Os gráficos abaixo foram elaborados diretamente dos dados constantes nos relatórios do Paebes TRI 2018 (ESPÍRITO SANTO, 2018b).

Gráfico 1 - Percentual geral de acerto da $1^{\text {a }}$ série do Ensino Médio Regular e Integrado no Paebes TRI 2018 - Matemática

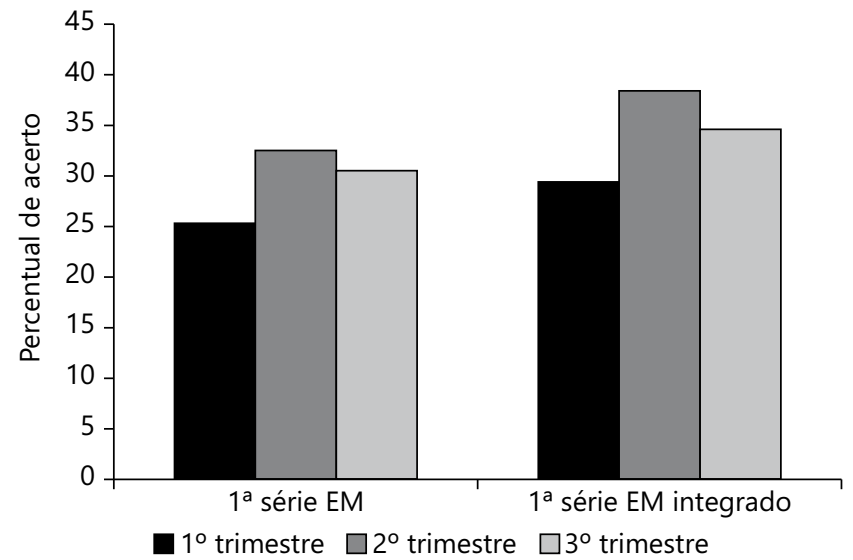

Fonte: Relatórios do Paebes Trimestral $2018-1^{\circ}, 2^{\circ}$ e $3^{\circ}$ trimestres

Gráfico 2 - Percentual geral de acerto da $2^{\mathrm{a}}$ série do Ensino Médio Regular e Integrado no Paebes TRI 2018 - Matemática

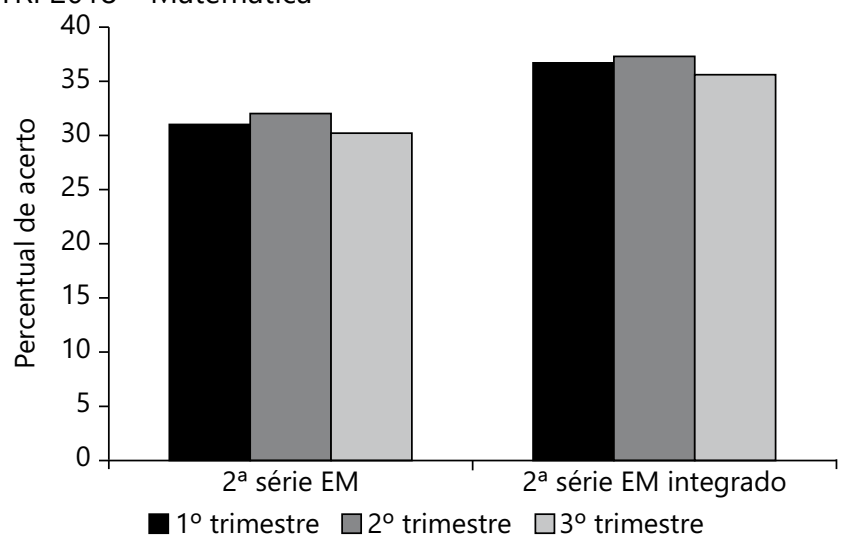

Fonte: Relatórios do Paebes Trimestral $2018-1^{\circ}, 2^{\circ}$ e $3^{\circ}$ trimestres 
Gráfico 3 - Percentual geral de acerto da $3{ }^{a}$ série do Ensino Médio Regular e Integrado e da $4^{a}$ série do Ensino Médio Integrado no Paebes Tri 2018 - Matemática

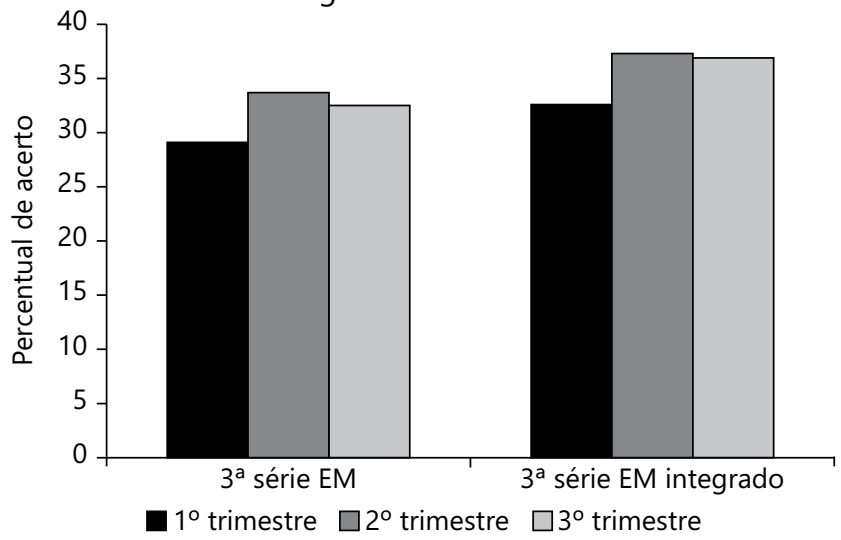

Fonte: Relatórios do Paebes Trimestral $2018-1^{\circ}, 2^{\circ}$ e $3^{\circ}$ trimestres 